\title{
Short Communication: Effects of 2-Hydroxy-4-(Methylthio) Butanoic Acid Isopropyl Ester on Milk Production and Composition of Lactating Holstein Dairy Cows
}

\author{
R. H. Phipps, ${ }^{* 1}$ C. K. Reynolds, ${ }^{*}$ D. I. Givens, ${ }^{*}$ A. K. Jones, ${ }^{*}$ P.-A. Geraert, $†$ E. Devillard,† and R. Bennett† \\ ${ }^{*}$ Centre for Dairy Research, School of Agriculture, Policy and Development, University of Reading, RG6 6AR, United Kingdom \\ †Adisseo, Commentry 03600, France
}

\begin{abstract}
Sixteen multiparous Holstein cows were used to determine the effects of 2-hydroxy-4-(methylthio) butanoic acid isopropyl ester (HMBi: 0 vs. $1.26 \mathrm{~g} / \mathrm{kg}$ of total ration dry matter $(\mathrm{DM})$ and dietary crude protein (CP) concentration [14.7\% (low) vs. $16.9 \%$ (standard), DM basis] on milk yield and composition using a replicated $4 \times 4$ Latin square design experiment with 4 -wk periods. Cows were fed ad libitum a total mixed ration with a 1:1 forage-to-concentrate ratio (DM basis), and diets provided an estimated 6.71 and $1.86 \%$ lysine and methionine, respectively, in metabolizable protein for the low-protein diet and 6.74 and $1.82 \%$ in the standard protein diet. Dry matter intake, milk yield, and composition were measured during wk 4 of each period. There were no effects on DM intake, which averaged $24.7 \mathrm{~kg} / \mathrm{d}$. There was an interaction between dietary $\mathrm{CP}$ and $\mathrm{HMBi}$ for milk yield and $3.5 \%$ fat-corrected milk (FCM). Feeding HMBi decreased milk and FCM yield when fed with the low-CP diet but did not affect milk or FCM yield when fed with the standard CP diet. Feeding HMBi increased milk protein concentration regardless of diet $\mathrm{CP}$ concentration and increased milk protein yield when added to the standard CP diet but not the low-CP diet. The positive effect of HMBi on milk protein yield was only observed at the standard level of dietary CP, suggesting other factors limited the response to HMBi when dietary protein supply was restricted.
\end{abstract}

Key words: dairy cow, methionine supplement, milk protein

The relative inefficiency with which $\mathrm{N}$ is used for milk production, coupled with the tendency to overfeed $\mathrm{CP}$ to help maximize milk production, can contribute to pollution through increased $\mathrm{N}$ excretion (St-Pierre and Thraen, 1999). Although a reduction in $\mathrm{N}$ excretion can

Received December 12, 2007.

Accepted June 23, 2008.

${ }^{1}$ Corresponding author: r.h.phipps@reading.ac.uk be achieved by decreasing the amount of dietary CP offered, this is generally associated with a reduction in milk and milk protein yield (Broderick, 2003).

Methionine and Lys have been shown to be limiting amino acids for milk yield and milk protein production (Schwab et al., 1992). When reviewing published data, St-Pierre and Sylvester (2005) noted that although 2-hydroxy-4-(methylthio) butanoic acid (HMB) had been used extensively as a source of supplemental Met in dairy cow diets, the response in terms of milk yield, milk protein, and milk fat varied and suggested that it may have been associated with variability in apparent rumen degradability of HMB. Robert et al. (2001) reported that the isopropyl ester of HMB (HMBi) had bioavailability (as metabolizable Met) values of around $50 \%$ in lactating dairy cows. The portion of $\mathrm{HMBi}$ not absorbed from the rumen is largely hydrolyzed to $\mathrm{HMB}$, which could improve rumen function, resulting in improved milk composition (Robert et al., 2002).

Results from short-term changeover design trials (Robert, 2005) have shown that milk protein content increased between 0.09 and 0.14 percentage units when cow diets were supplemented with HMBi. In these trials, there were no effects of HMBi on DMI, milk yield, or milk fat content. However, in a continuous design lactation study, HMBi fed at $1.5 \mathrm{~g} / \mathrm{kg}$ total ration DM did not affect DMI but increased milk yield and milk protein content (St-Pierre and Sylvester, 2005). Although the response in milk protein content was almost immediate, milk yield response was gradual and only reached significance after $11 \mathrm{wk}$ of supplementation. Feeding HMBi numerically increased milk fat concentration, and although the effect was not significant, the increase in FCM observed was greater than the increase in milk yield. In addition, supplementation with $\mathrm{HMB}$ and HMBi improved the efficiency of $\mathrm{N}$ utilization (St-Pierre and Sylvester, 2005).

From both an economic and environmental standpoint, there is interest in determining whether a decreased dietary CP concentration together with a metabolizable Met supplement would support milk protein production to the same extent as an unsupplemented 
standard $\mathrm{CP}$ diet, thereby improving $\mathrm{N}$ utilization. The aim of the current study was to determine the effects of HMBi (Metasmart, Adisseo, Commentry, France) on feed intake, milk yield, and milk composition of Holstein dairy cows receiving a TMR with either a low or standard dietary $\mathrm{CP}$ concentration and to ascertain if performance can be maintained when feeding $\mathrm{HMBi}$ with lower-protein diets.

The work was conducted under the authority of the UK Animals (Scientific Procedures) Act 1986. Cows were housed in a free-stall barn with sawdust for bedding and with ad libitum access to potable water. Sixteen multiparous Holstein cows (DIM: $72 \pm 16$, BW: 640 \pm 47.8 , and milk yield: $45.0 \pm 2.95 \mathrm{~kg} / \mathrm{d}$ ) were allocated to a $4 \times 4$ Latin square experiment with 4 simultaneous independent squares, balanced for carryover effects, and with periods lasting $4 \mathrm{wk}$ to determine the effect of HMBi (0 vs. $1.26 \mathrm{~g} / \mathrm{kg}$ of total ration DM) and dietary CP content [low protein (LP) vs. standard protein (SP)] on feed intake, milk yield, and composition using a $2 \times$ 2 factorial arrangement giving 4 treatments (LP, LP $+\mathrm{HMBi}$, SP, SP + HMBi). The HMBi was fed as the commercial product MetaSmart Dry (Adisseo), with a minimum guarantee of $95 \%$ HMBi monomers, supplied as a $60 \%$ premix with silica as an inert carrier. MetaSmart Dry was included in the concentrates at a rate of $4.2 \mathrm{~g} / \mathrm{kg}$ of concentrate DM. This was equivalent to 2.1 $\mathrm{g} / \mathrm{kg}$ of total ration DM, given that the ration contained $50 \%$ concentrates on a DM basis. This resulted in an $\mathrm{HMBi}$ monomer concentration in the total ration of $1.26 \mathrm{~g} / \mathrm{kg}$ of DM, which provided an extra $11.7 \mathrm{~g} / \mathrm{d}$ of metabolizable Met. This inclusion rate is very close to that used by St Pierre and Sylvester (2005). All cows received a TMR containing corn silage and grass silage in a ratio of 3:1 (DM basis) and containing a 50:50 mixture of forage:concentrate (DM basis; Table 1). The CP content of LP diets was $14.7 \%$ DM compared with the SP diets of $16.9 \%$ DM (Table 1). Before the addition of $\mathrm{HMBi}$, diets were estimated to provide 6.71 and $1.86 \%$ Lys and Met, respectively, in metabolizable protein in the LP diet and 6.74 and $1.82 \%$ in the SP diet calculated using the feed-into-milk model (Thomas, 2004). Basal dietary $\mathrm{CP}$ concentration was altered by varying the inclusion rates for rapeseed meal and rumen-protected (formaldehyde-treated) soybean meal (Sopralin, 52\% $\mathrm{CP}, 40 \%$ digestible undegradable protein, DM basis, Trouw Nutrition, Northwich, Cheshire, UK). In wk 4 of each period, daily samples (250 g/sample) of corn silage, grass silage, and the concentrate mixture fed were composited to form a representative sample for each period and frozen $\left(-20^{\circ} \mathrm{C}\right)$. Silage samples were analyzed for nutritional characteristics (Eurofins Laboratories, Woodthorne, Wolverhampton, UK). Oven-dried $\left(60^{\circ} \mathrm{C}\right.$ until static weight) silage samples were
Table 1. Formulation and composition (\% of DM unless stated otherwise) of low-protein (LP) and standard protein (SP) diets

\begin{tabular}{lcr}
\hline Item & LP & SP \\
\hline Ingredient & & \\
Corn silage & 37.5 & 37.5 \\
Grass silage & 12.5 & 12.5 \\
Cracked corn & 14.5 & 14.5 \\
Rapeseed meal & 0 & 1.2 \\
Soybean meal & 10.4 & 10.4 \\
Molassed sugar beet pulp & 13.4 & 9.4 \\
Wheat middlings & 9.7 & 8.5 \\
Sopralin ${ }^{1}$ & 0 & 4.0 \\
Minerals & 2.0 & 2.0 \\
Composition, \% of DM & & \\
ME, MJ/kg of DM & 11.5 & 11.9 \\
CP & 14.7 & 16.9 \\
Starch & 25.6 & 25.5 \\
NDF & 30.1 & 30.1 \\
Water-soluble carbohydrate & 6.0 & 5.5 \\
Ash & 8.8 & 8.7 \\
Ether extract & 3.3 & 3.5 \\
\hline
\end{tabular}

${ }^{1}$ Formaldehyde-treated soybean meal (Trouw Nutrition, Northwich, Cheshire, UK).

${ }^{2}$ Contained (g/kg): calcium 270, phosphorus 40, magnesium 60, sodium 40 and $(\mathrm{mg} / \mathrm{kg})$ cobalt carbonate 50 , calcium iodate 500, manganese oxide 4,000 , zinc oxide 5,000 , cupric sulfate 1,500 and (IU/kg) 500,000 vitamin $\mathrm{A}, 100,000$ vitamin $\mathrm{D}_{3}, 1,000$ vitamin $\mathrm{E}$.

analyzed for DM, CP, NDF, starch, and water-soluble carbohydrates, using near-infrared spectroscopy (Foss 5000 NIR Systems, York, UK). The ME concentration for grass silage, corn silage, and concentrate supplement was estimated according to Offer et al. (1996) and Givens et al. (1995). The concentrate supplement was analyzed for DM, CP, NDF, starch, water-soluble carbohydrates, and oil content using wet chemistry methods, and ME content was estimated (Ministry of Agriculture Fisheries and Food, 1993). These results were used to calculate the nutritional content of the TMR offered during the experimental periods (Table 1).

Fresh TMR were prepared daily and offered on an individual cow basis at $0900 \mathrm{~h}$ using an electronic feeding system (American Calan, Northwood, NH). Cows were fed for ad libitum intake (5 to $10 \%$ refusals), and refusals were removed (0700 h) and weighed on Monday, Wednesday, and Friday. Cows were milked twice daily at 0500 and $1500 \mathrm{~h}$ through a 50-point rotary parlor (Dairymaster, Causeway Co., Kerry, Ireland). Individual milk yields were recorded automatically for all cows at each milking. In wk 4 of each period, $25-\mathrm{mL}$ milk samples were collected at 8 milkings (Wednesday p.m. to Friday a.m. and Monday p.m. to Wednesday a.m.) and analyzed for fat, protein (total $\mathrm{N} \times 6.38$ ), and lactose concentration using an infrared milk analyzer (Foss Electric, York, UK). The mean milk composition values for the 8 milk samples analyzed were combined with the mean weekly milk yields to calculate mean 
Table 2. Effects of dietary CP and 2-hydroxy-4-(methylthio) butanoic acid isopropyl ester (HMBi) supplementation on DMI and milk production of dairy cows

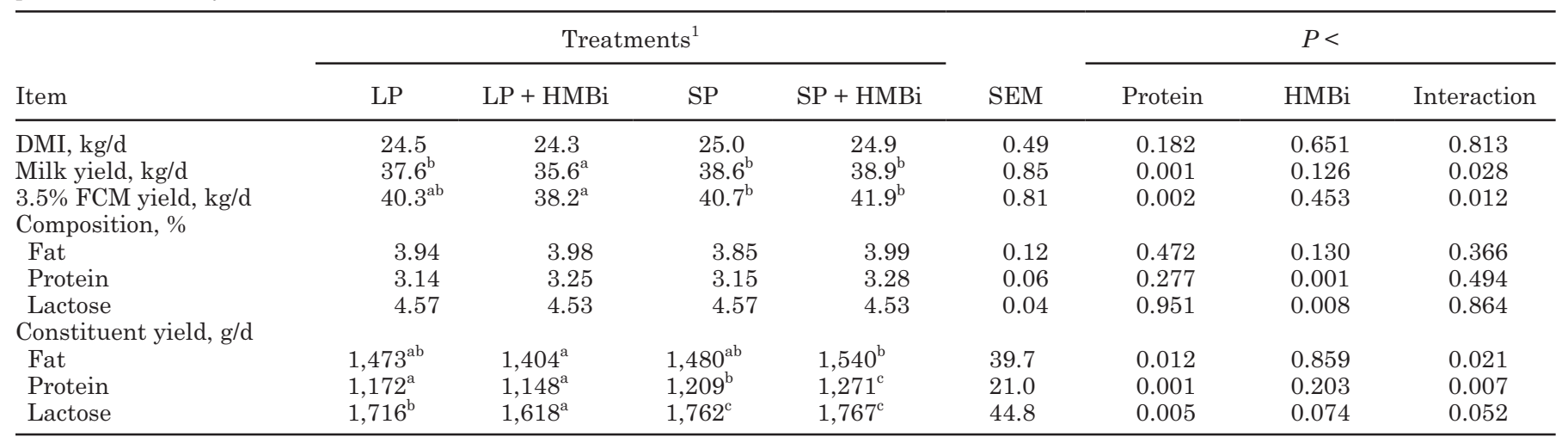

${ }^{a-c}$ Means within a row with different superscripts differed $(P<0.05)$.

${ }^{1}$ Treatments were low (LP) or standard (SP) dietary CP (14.7 or 16.9\%, DM basis, respectively) without or with HMBi supplementation (1.26 $\mathrm{g} / \mathrm{kg}$ of diet DM).

weekly milk composition data. One cow was removed from the study after the first period because of chronic mastitis, and all data associated with this animal were excluded from the analysis. Data were analyzed as 4 simultaneous $4 \times 4$ Latin squares using the MIXED procedure of SAS (SAS Institute, 2007) and a model testing random effects of cow and fixed effects of period, diet $\mathrm{CP}$ concentration, HMBi supplementation, and $\operatorname{diet} \mathrm{CP} \times \mathrm{HMBi}$ interaction. The interaction between diet $\mathrm{CP}$, HMBi supplementation, and period was not significant for any variable $(P>0.20)$ and therefore was removed from the statistical model used. When the diet $\mathrm{CP} \times \mathrm{HMBi}$ interaction was significant, means were separated using Tukey-adjusted least squares mean comparisons within the MIXED procedure. Differences were declared at $P<0.05$.

There was no effect of dietary CP concentration or the HMBi supplement on DMI (Table 2). There was an interaction between dietary $\mathrm{CP}$ concentration and the HMBi supplement for milk yield $(P=0.03)$ and FCM $(P<0.02)$. Feeding HMBi decreased milk yield and tended to decrease FCM $(P<0.09)$ when the LP diet was fed but not when the SP diet was fed (Table 2). The interaction between dietary $\mathrm{CP}$ concentration and the inclusion of HMBi for milk and FCM yield contrasts with other work (Leonardi et al., 2003), in which there was no significant interaction between dietary $\mathrm{CP}$ concentration and Met supplementation. This may have been due to the fact that Leonardi et al. (2003) used not only a different source of Met (rumen-protected DL-Met, Mepron M85, Degussa Corp, Allendale, NJ) but also provided greater dietary CP concentrations (16.1 and $18.8 \%$, DM basis) compared with those used in the current study (14.7 and $16.9 \%$, DM basis). This suggests that when the low-CP diet was fed in the present study, other factors such as the supply of RUP or Lys and (or) other amino acids in metabolizable protein may have been limiting, and not just Met supply. In addition, differences in RDP or fermentable carbohydrates between the LP and SP diets may have influenced the response to HMBi in the present study.

The results of the present study are in contrast to the results reported by St-Pierre and Sylvester (2005), who observed increases in milk yield and FCM yield of 2.9 and $4.5 \mathrm{~kg} / \mathrm{d}$, respectively, when HMBi was fed. These increases were attributable to a progressive response in milk yield, which reached significance only at wk 11 of the 16-wk continuous designed study. Based on this result, it is unlikely that a milk yield response associated with the inclusion of HMBi could be fully achieved in the current study that employed a Latin square experiment with 4 -wk periods. Further studies are needed to determine the potential milk yield response to the inclusion of HMBi and to explore factors such as stage of lactation that might affect the rate of increase in milk yield response. Supplementation with HMBi increased milk protein concentration by 0.12 percentage units $(P<0.001)$, which supports results of previous experiments with HMBi (St-Pierre and Sylvester, 2005). There was a significant interaction between dietary $\mathrm{CP}$ concentration and inclusion of $\mathrm{HMBi}$ for milk protein yield $(P<0.007)$. In the SP diet, HMBi increased milk protein yield by $62 \mathrm{~g} / \mathrm{d}(P<0.001)$, reflecting the increase in milk protein concentration and a numerical increase in milk yield, but had no effect when the LP diet was supplemented. Although this increase in milk protein yield for the SP diet is about half of that noted by St-Pierre and Sylvester (2005), the increase in milk yield in the current study was markedly less, due in part to the short-term nature of 
the present study. As observed previously (Leonardi et al., 2003), a dietary supplement of metabolizable Met did not negate a negative effect of decreased dietary CP on milk protein yield. As indicated previously, this may reflect the use of changeover designs in these studies or other limitations imposed by the changes in dietary ingredients accompanying the reduction in dietary CP. Based simply on average amounts of dietary protein consumed and milk protein produced in the present study, milk protein yield accounted for a greater portion of protein intake for the LP diet compared with the SP diet and was increased slightly $(1.6 \%)$ when HMBi was fed with the SP diet (32.5, 32.1, 28.6, and $30.2 \%$ for $\mathrm{LP}, \mathrm{LP}+\mathrm{HMBi}$, SP, and SP + HMBi, respectively). Increased efficiency of dietary $\mathrm{N}$ utilization when dietary protein concentration is decreased has been widely reported (Broderick, 2003; Leonardi et al., 2003).

Neither the current study nor that of St-Pierre and Sylvester (2005) established significant treatment effects of HMBi on milk fat concentration. As already indicated for FCM yield, in the present study, there was a significant interaction between diet $\mathrm{CP}$ and HMBi for milk fat yield $(P<0.03$; Table 2$)$, with milk fat yield being greater for SP + HMBi compared with $\mathrm{LP}+\mathrm{HMBi}$. This difference in yield of milk fat primarily reflected differences in milk yield, because milk fat concentration was not affected $(P>0.13)$, and again may reflect an interaction between dietary supply of rumen-degradable substrates and effects of HMBi.

In conclusion, when diets with a standard CP concentration were fed to Holstein cows in early lactation, the inclusion of $\mathrm{HMBi}(1.26 \mathrm{~g} / \mathrm{kg}$ of total ration DM) increased milk protein concentration and yield. The interaction between dietary $\mathrm{CP}$ concentration and inclusion of HMBi, in which the increase in milk protein yield was not observed with the LP diet due to a decrease in milk yield, suggests that other factors limited the response to HMBi when dietary CP supply was restricted.

\section{ACKNOWLEDGMENTS}

We thank Adisseo (Commentry, France) for financial support to conduct the study, Sarah Potterton and Jon Siviter (University of Reading) for technical help during the study, and Rosemary Elliott (consultant statistician) for the statistical analyses.

\section{REFERENCES}

Broderick, G. A. 2003. Effects of varying dietary protein and energy levels on the production of lactating dairy cows. J. Dairy Sci. 86:1370-1381.

Givens, D. I., B. Cottyn, P. J. S. Dewey, and A. Steg. 1995. A comparison of the neutral detergent-cellulase method with other laboratory methods for predicting the digestibility in vivo of maize silage from three European countries. Anim. Feed Sci. Technol. 54:55-64.

Leonardi, C., M. Stevenson, and L. E. Armentano. 2003. Effect of two levels of crude protein and methionine supplementation on performance of dairy cows. J. Dairy Sci. 86:4033-4042.

Ministry of Agriculture Fisheries and Food. 1993. Prediction of Energy Values of Compound Feedstuffs for Farm Animals. Booklet 1285. Her Majesty's Stationery Office, London, UK.

Offer, N. W., B. R. Cotterill, and C. Thomas. 1996. Relationship between silage evaluation and animal response. Pages 26-38 in Proc. 11th Int. Silage Conf., Inst. Grassland Environ. Res., Aberystwyth, UK.

Robert, J.-C. 2004. Metabolizable methionine optimization of dairy cow rations. Pages 223-254 in Recent Advances in Animal Nutrition. P. C. Garnsworthy and J. Wiseman, ed. Nottingham University Press, Nottingham, UK.

Robert, J.-C., N. Ballet, C. Richard, and B. Bouza. 2002. Ruminal metabolism of 2-hydroxy-4 (methylthio) butanoic acid isopropyl ester (HMBi). J. Dairy Sci. 85(Suppl. 1):240. (Abstr.)

Robert, J.-C., C. Richard, and B. Bouza. 2001. Influence of monomer and dimmer forms of isopropyl ester of HMB on the supply of metabolizable methionine to the blood of ruminants. J. Dairy Sci. 84(Suppl. 1):281. (Abstr.)

SAS Institute. 2007. SAS User's Guide: Statistics. Version 9.1. SAS Institute Inc., Cary, NC.

Schwab, C. G., C. K. Bozak, N. L. Whitehouse, and V. M. Olson. 1992. Amino acid limitations and flow to the duodenum at four stages of lactation. 1. Sequence of lysine and methionine limitation. J. Dairy Sci. 75:3486-3502.

St-Pierre, N. R., and J. T. Sylvester. 2005. Effects of 2-hydroxy-4(methylthio) butanoic acid (HMB) and its isopropyl ester on milk production and composition by Holstein cows. J. Dairy Sci. 88:2487-2497.

St-Pierre, N. R., and C. S. Thraen. 1999. Animal grouping strategies, sources of variation and economic factors affecting nutrient balance on dairy farms. J. Anim. Sci. 77(Suppl. 2):72-83.

Thomas, C. 2004. Feed into Milk: A New Applied Feeding System for Dairy Cows. Nottingham University Press, Nottingham, UK. 